\title{
Discussion about Interdisciplinary General Education Curriculum Model— Take the Curriculum Design and Expression of Industrial Products in Ningbo University as an Example
}

\author{
Li Liu \\ The faculty of Mechanical Engineering and Mechanics,Ningbo University,Ningbo city of Zhejiang Province,China,Pd; \\ 315211 \\ liuli@nbu.edu.cn
}

\begin{abstract}
Interdisciplinary breadth and increase capacity of general education enable graduates to settle unprecedented new problems by creative ways so as to cause supplementary effect with might doubled to professional education. In the article, the curriculum Design and Expression of Industrial Products in Ningbo University is taken as an example to illustrate practices and experience of general education in Chinese universities in angle of purpose, content and execution of curriculums so as to push forward theoretical researches and practices.
\end{abstract}

Keywords- general education, design and expression of industrial products, practical experience

\section{INTRODUCTION}

General education and professional education are two kinds of relative modes for personnel training. The latter focuses on professional skills; while the former focuses on integrated development[1]. In light of superior and traditional advantages of professional education in the higher education system in our country, general education can be taken as an auxiliary means to cultivate professionals-extensively enlarging knowledge, broadening horizon, exploring thinking, motivating inspiration, promoting boundary and cultivating quality[2-3]. Interdisciplinary breadth and increase capacity of general education enable graduates to settle unprecedented new problems by creative ways so as to cause supplementary effect with might doubled to professional education[4].

Since the working seminar about strengthening experimental units of cultural quality-oriented education in colleges and universities in 1995 was held in Huazhong University of Science and Technology, explorations about theory and practices of general education have passed for 15 years[5]. Some universities have started to explore and practice based on mirroring overseas practices of general education. In the article, the curriculum Design and Expression of Industrial Products in Ningbo University is taken as an example to illustrate practices and experience of general education in Chinese universities in angle of purpose, content and execution of curriculums so as to push forward theoretical researches and practices.

\section{PURPOSE}

The curriculum Design and Expression of Industrial Products in Ningbo University is a curriculum about quality-oriented education opened for students in liberal arts and non-enginery subjects; which aims at enabling them to learn engineering thinking and use it to consider problems in engineering chains so as to broaden thinking; understanding connotation and processes about designing products, manufacturing technology and pattern expression of products so as to harbor background of modern engineering; strengthening interinfiltration and integration of arts and science education, establishing engineering concept of students and raising their overall quality.

\section{CONTENT AND TEACHING METHOD, MEANS}

Teaching content is the lifeline of teaching effect. The curriculum is carried out with three mainlines: product design, product expression and manufacturing and basically covers knowledge about design and production of industrial products. Meanwhile, it makes overall arrangements in teaching targets and teaching content, focuses on the fewer and the better and emphasizes on conciseness and structuralization of knowledge. In chapter 1, design method and creative thinking is the core and rich cases are introduced based on theories. Cases are small or big; the big reflects development and process of design; while the small reflects wonderful originalities. Theories and practices are closely connected through cases and explain the profound in simple terms; furthermore, cases approaching to life can arouse interest of students, integrate knowledge points combined with design exercises of small items and promote initial study of students, their skills and quality in internal communication and cooperation. Chapter 2 about product manufacturing and processing is introduced combined with videoatape and visit based on traditional introduction, which is not only intuitional and vivid but also raises efficiency; graphical expression in chapter 3 mainly introduces computer drawing of simple two dimension engineering pattern and solid modeling of three-dimensional computer.

In light of teaching content, multimedia teaching, field visit, special training, design of small items and defence are applied; teaching methods are flexible and diverse; creative capacity and overall quality are focally raised.

\section{EXECUTION AND EFFECT}

The curriculum has been opened for 6 times in total since it was applied for a general education curriculum in 
Ningbo University in 2005, which has unceasingly revised and perfected teaching arrangements through teaching execution and reform in the past years. Teaching content mainly focuses on drawing engineering drawing and reading in the beginning; expands to organization, implementation and management of design teams of products and creative thinking then. In the first place, it broadens knowledge points in content and desalts professional color in depth, aiming at enable students in different majors (including arts and science) to understand design concept and process, execution of products, organization and management of design teams so as to learn to consider problems in engineering chains by engineering thinking; meanwhile, design and creative schemes and team design play a positive role in broadening thinking of students and raising communication and cooperation between teams. Then, leading knowledge and engineering cases are supplemented in the teaching and are carried out combined with engineering cases and design exercises of small items. Product design is experienced combined with design of small items, which can not only simulate organization, implementation and management of design teams but also can strengthen ability training of students to acquire and use knowledge, incentive exploration ability and creative consciousness of students and cultivate their cooperation and expression ability etc.

There will be appraisal and assessment instead of exam in the curriculum. The assignment is carried out by special training (3 times) combined with design of small items (3 times); total performance in the above is the permanence appraisal.

Special training is mainly arranged in computer drawing of industrial product materials and simple two dimensional engineering drawings. The former is complex and relatively boring. In the teaching, cases approaching life are supplemented to lead students to discuss study. For example, steel Q460 in the bird's nest and material evolution of the vaulting pole in the pole vault are taught; special assignments are arranged after class so that students can discover new materials and their application of products. In that case, common materials and new materials of industrial products can be comprehensively understood in few class hours; and students' strong interest in study is aroused.

Small items are designed in groups. For instance, in the autumn semester in 2011, students were divided in to 9 groups with 9 10/ group; students in arts and science were collocated reasonably. Groups conducted survey and conclusion, proposed design schemes and made design expression. The expression way was not limited: two dimensional graphical representation, three dimensional modeling, animation demonstration, reference representation, hand drawing and photograph etc can be chosen

Table 1 Statistical chart of grade

\begin{tabular}{|c|c|c|c|c|c|l|l|}
\hline \multirow{2}{*}{ Assignment 1 } & \multicolumn{5}{|c|}{ Student's evaluation } & Teacher's & \multirow{2}{*}{ Group score } \\
\cline { 2 - 8 } & Group 1 & Group 2 & Group 3 & $\ldots$ & Average value & evaluation & \\
\hline Group 1 & & & & & & & \\
\hline Group 2 & & & & & & & \\
\hline Group 3 & & & & & & & \\
\hline$\ldots$ & & & & & & & \\
\hline
\end{tabular}

according to skills of groups. The design result is defended in the class; appraisal from students and the teacher covers a half of the grade and the statistical chart takes on as table 1 :

For example, in the improvement design assignment of the washing machine group which is set in light of creative thinking of products, group 9 conducts the following improvement (Fig.1, Fig.2) in consideration of simple operation from starting points that the control panel of the washing machine is controlled by one button in several options for several times; it wastes time; repeated use of one button would reduce its service life; the initial button an the power switch are often in a row so that the user would press the wrong button usually; if the power is cut suddenly, reset would eliminate all settings and we need to input all settings again.

Schemes mainly start from experience in using the mashing machine and design originalities are proposed.
There are analytic demonstration and graphical representation. 6 students in a group cooperate with each other closely and finish design assignments

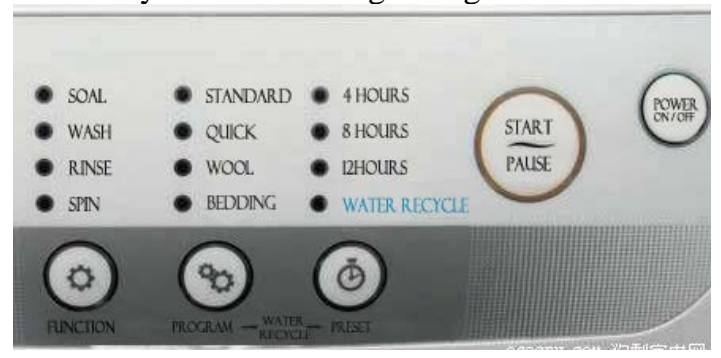

Fig. 1 Existing design 


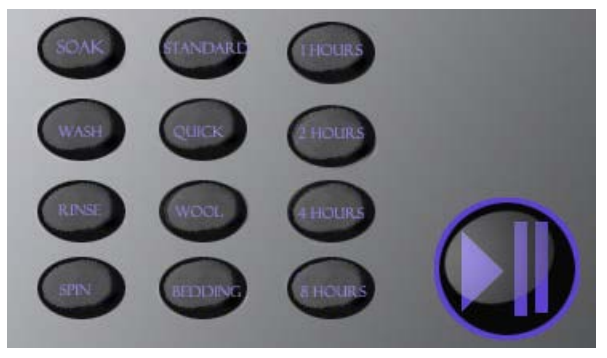

Fig. 2 Improved design

excellently so as to win consistent praise of other groups through design defence. Then, the works is recommended to be applied as a scientific research item and teachers good at controlling technical design are recommended as the instructor for post preparation.

For instance, the group in chair design is set in light of ergonomics. Many groups have conducted extensive investigation about disadvantages and use requirements of chairs in dormitories and classrooms in universities through questionnaire, network and interview so as to acquire first hand information and proposed improvement schemes, among which there are lots of excellent originalities; for example, in the spring semester in 2009, group 8 proposed growing chairs combined with several standard unit models through connecting pieces. Originality is infinite; as long as we incentive brains of students, their achievements would usually be beyond our imagination.

In the study of the curriculum, arrangements of engineering cases and design practices are welcomed by students very much. In the defence class, students strive to be the first to speak; splendid debates further push forward their interest in studying the curriculum. Groups with lower scores in the first debate made more efforts in next assignments. In the last design defence, comprehensive ability of all groups can be raised obviously.

\section{CONCLUSION}

According to the statistic of 6 classes, most students choose industry and commerce, accounting, finance, economics, business administration, marketing, international trade, logistics, arts design (arts) and administrative management etc.; most upperclassmen choose Chinese, history, physics, mathematics, biotechnology, resource circulation, English, Japanese, computer, communication, civil engineering, automation and law and so on. In study, student in arts generally reflect that the curriculum is a brand new course, its teaching content has been never contacted and its teaching method is novel. In the beginning, students in arts accept the curriculum more slowly than students in science; while their interests are increasingly strong; some students combine knowledge with daily life and gradually establish sense of engineering. Lots of students in arts reflect that knowledge about pure arts in their brains has been motivated and; a brain revolution has been conducted through the study of the course; furthermore, they learn about thinking of engineering disciplines so as to broaden their thinking. The study mode combined with design of small items and independent defence strengthen ability training of students in acquiring and using knowledge, arouse their exploration ability and sense of originality. Meanwhile, it cultivates their ability in cooperation, expression and defence; their integrated quality is further raised; course study and appraisal are reached. Although the curriculum is opened as the general education course and students pay high attention, they study it just for credit hour because their learning positivity is bad; their learning attitude is careless; they do not concentrate on classes even stay away from school etc.

\section{REFERENCES}

[1] CHU Xiao-hong, MA Liang, LIU Cheng-xin, "Evolution of Technology Curriculum and the Inspiration for General Education”, Modern Educational Technology, vol. 21, Feb.2011,pp.45-47,51.

[2] TONG Bing-shu, GAO Shu-feng, "Discussion on Innovation Ability Cultivation for Students in Teaching of Engineering Graphics”, Journal of Engineering Graphics, vol. 6, June.2008,pp.1-6.

[3] ZHOU Hong, YANG Hanxin, "The Orientation of General Education Game between Means and Purpose”, Academy , Feb.2011, pp.42-47 (In Chinese).

[4] ZHANG Qi-ren, “General Education Chang of the Objectives and Contents”, Academy, Feb.2011, pp.48-53 (In Chinese)

[5] Fang Mingsheng, “The construction of the liberal Education Curriculum of Human Development under the Techer Education Curriculum Standards: Based on the Teaching Material of Children's World”, Research in Educational Development, vol.18, 2014,pp.63-68. 